\title{
Magnetic and Radiometric Characterization of the São Bento dos Torres Mafic Suite (MG) and associations to the Ti-V Occurrence.
}

Dutra, A.C.D. ${ }^{1}$, Guimarães, S.N.P. ${ }^{2}$, Marinho, L. H. C. ${ }^{1}$, Mane, M. A. ${ }^{1}$, Salomão, M. ${ }^{1}$

${ }^{1}$ Department of Geology, University of Rio de Janeiro State (UERJ)

2 Department of Geophysics, National Observatory (ON/MCTI)

Copyright 2021, SBGf - Sociedade Brasileira de Geofísica.

This paper was prepared for presentation during the $17^{\text {th }}$ International Congress of the Brazilian Geophysical Society held in Rio de Janeiro, Brazil, 16-19 August 2021.

Contents of this paper were reviewed by the Technical Committee of the $17^{\text {th }}$ International Congress of the Brazilian Geophysical Society and do not necessarily represent any position of the SBGf, its officers or members. Electronic reproduction or storage of any part of this paper for commercial purposes without the written consent of the Brazilian Geophysical Society is prohibited.

\section{Abstract}

The São Bento dos Torres Suite, located in the Aracitaba region (Minas Gerais, Brazil), represents a sequence of metabasic rocks interlayered with banded orthogneisses. The region has a metagabbro exploration history, informally called "granites"; however, this work focuses on a Vanadium Anomaly of $720 \mathrm{ppm}$, found in studies carried out by Pinto (1991) in the area.

Petrographic analysis allowed the characterization of the basic lithotypes found in the region such as gabbro, garnet metagabbro, garnet amphibolite, garnet granulitic, a range of orthognaisse, designated as biotite alkali gneiss (hornblende) and biotite gneiss (sphene). The aerogeophysical interpretation associated with the geological study, gave rise to the interpretative lithogeophysical map, illustrated in Figure (1), where the vanadium anomaly are pointed out and characterized.

\section{Results and Conclusions}

The structural framework of the study region, revealed from interpretive geophysical techniques applied to aeromagnetic data, shows that the region reflects predominantly in two directions: NW-SE and NE-SW. The NW-SE direction is related to intensely deformed areas, whereas the NE-SW pattern is associated with late deformational phases.

The vanadium anomaly mentioned is associated with the low magnetic amplitude domain, coinciding with the $G$ lithogeophysical unit, identified in the generated lithogeophysical model, associated with the drainage area and geologically characterized by the presence of the banded biotite gneiss lithotype.

This fact may suggest that the lithotype used for sampling was near the drainage, having been transported a short distance, since the $\boldsymbol{H}$ unit, referring to the basic character lithotypes and is found in the adjacencies.

Bearing in mind that the great Ti-V mineralizations known in the world, they are hosted under the context of layered intrusions of gabbro anortositic composition associated with metagabbro, pyroxenites, orthogneisses among other igneous lithotypes (Charlier et al, 2015), this vanadium anomaly, brings to light a new approach to mineral exploration in high-grade metamorphic land, belonging to the Ribeira Belt.

Within this premise, the basic rocks in the Aracitaba region became metallotects for the occurrence of vanadium, where all the procedures of the exploratory campaign aimed to highlight these rocks, to provide to enhance this occurrence, and to suggest aspects about the origin.

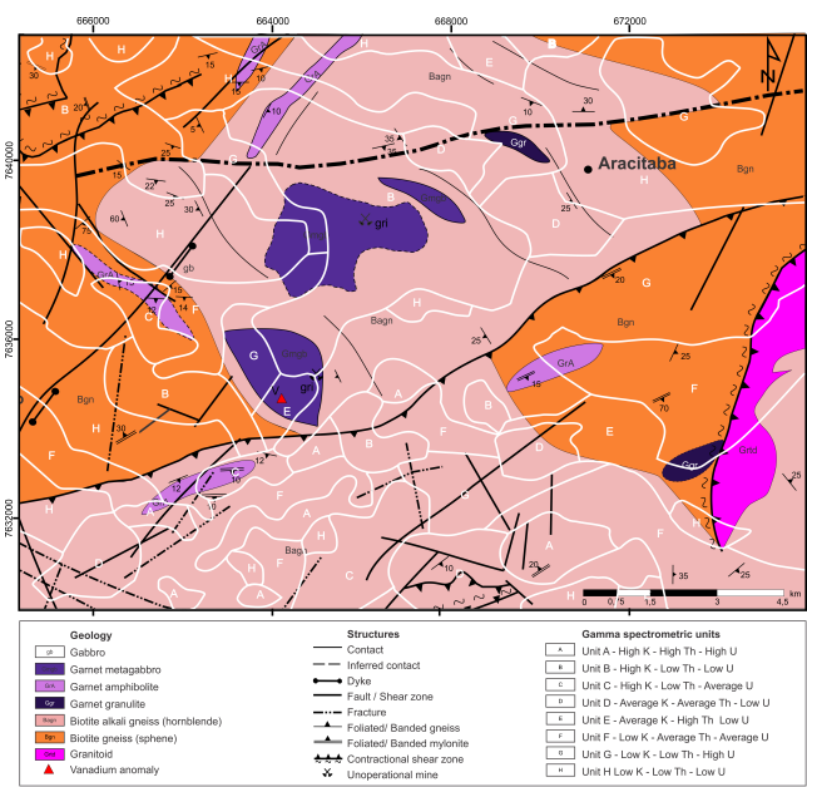

Figure (1) - Lithogeophysical Model of the study area built from the correlation between the ternary radiometric and the geological maps. 